\title{
O TRABALHO HUMANO NA INTERFACE DOS \\ ESTADOS LIBERAL E SOCIAL E O DESDOBRAMENTO \\ DE SUA VALORIZAÇÃO NA CONSTITUIÇÃO DE $1988^{*}$
}

\section{HUMAN WORK IN THE INTERFACE OF THE LIBERAL AND SOCIAL STATES AND THE REFLECTIONS OF ITS VALORIZATION IN THE 1988 CONSTITUTION}

\author{
Clodomiro José Bannwart Júnior* \\ Sharon Cristine Ferreira de Souza
}

\begin{abstract}
Resumo: Ressalta-se a concepção de trabalho a partir da Teoria Social Crítica de Jürgen Habermas, destacando a importância do mesmo no processo de autoconstituição das sociedades humanas. Ainda no plano geral da análise, acompanha-se o desdobramento do Estado moderno, enfatizando a configuração dos Estados Liberal e Intervencionista. Nesse último, sobretudo, após a crise do liberalismo na primeira metade do século passado, busca-se realçar o papel de intervenção do Estado no domínio econômico, trazendo a discussão para o âmbito das Constituições brasileiras, com destaque especial à Constituição de 1988, no seu Art. 170, à luz da valorização do trabalho humano.
\end{abstract}

Palavras-chave: Trabalho. Estado Liberal. Estado Intervencionista. Constituição.

Abstract: This work focuses on the conception of work from the Critical Social Theory by Jürgen Habermas, highlighting its importance in the process of self-constitution of the human societies. In the general level of analysis, this study observes the effects of the modern State, emphasizing the configuration of the Liberal and Interventionist States. Regarding the latter, mainly after the liberalism crisis in the first half of the last century, this work seeks to highlight the role of the State intervention in the economic domain, directing the discussion to the ambit of the Brazilian Constitutions, particularly the 1988 Constitution, Art. 170, in the light of the valorization of the human work.

Key-words: Work. Liberal State. Interventionist State. Constitution.

Este artigo é resultado de estudos realizados no projeto de pesquisa "Estado e relações empresariais: diálogos filosóficos e jurídicos diante da regulação estatal sobre a ordem econômica nacional" do Curso de Mestrado em Direito Negocial da Universidade Estadual de Londrina.

" Doutor em Filosofia pela Universidade Estadual de Campinas; Professor do Departamento de Filosofia e do Programa de Mestrado em Direito Negocial da Universidade Estadual de Londrina. Email: cbannwart@hotmail.com

"Mestre em Direito Negocial e Especialista em Direito do Estado, ambos, pela Universidade Estadual de Londrina. Email: sharon_cris@uol.com.br 


\section{A DIALÉTICA DO TRABALHO NA VISÃO DA TEORIA SOCIAL CRÍTICA}

Nos escritos do jovem Hegel de Jena, a categoria "trabalho" aparece ao lado de outras duas categorias - linguagem e interação - e juntas representam a tríplice identidade da consciência, consideradas respectivamente como consciência astuta, consciência que nomeia e consciência reconhecida. Os três tipos de consciência assim apresentados constituem o processo dialético do trabalho, da representação e da luta pelo reconhecimento (HABERMAS, 1968, p. 30). A dialética da representação e do trabalho é alicerçada na relação entre sujeito e objeto e mediada por símbolos lingüísticos e instrumentos de trabalho, os quais colocam o sujeito diante da natureza (objeto) numa relação de exterioridade e de apropriação. Já a dialética da luta pelo reconhecimento é resultado da interação na qual a autoconsciência fixa-se na base de um reconhecimento recíproco, onde a identidade do 'eu' depende necessariamente da identidade do 'outro' e vice-versa.

Marx manteve-se na esteira do pensamento hegeliano, no entanto, revendo a conexão entre trabalho e interação mediante a dialética entre forças produtivas e relações de produção. Mesmo assim, a categoria 'trabalho' continuou prevalecendo na leitura marxista como elemento chave para a compreensão da autoformação social sob a rubrica das condições materiais da existência humana.

Já a linguagem detém em si as condições para a intersubjetividade ou interação, diferentemente da categoria 'trabalho' que determina o modo específico de o ser humano relacionar-se com a natureza. Portanto, o processo de autoformação dos seres humanos em sociedade ou o desenvolvimento da cultura humana passa necessariamente por estes dois conceitos chaves (GIDDENS, 1995, p. 246-247).

A idéia, portanto, de que a espécie humana enquadra-se em um processo de preservação e de reprodução permite entender que a mesma integra-se a um decurso evolutivo que se efetua continuamente pelas duas condições essenciais da existência: o trabalho e a interação. Nesse sentido, deve-se considerar que a realidade social constitui-se existencialmente por estas duas categorias ou condições. Trabalho e interação integram quase que condições transcendentais ao especificarem os meios de reprodução - material e simbólico - do gênero humano.

A categoria trabalho é integrada ao sistema de ação instrumental e busca satisfazer a tudo aquilo que é passível de controle e de produção de conhecimentos tecnicamente utilizáveis. O trabalho, nesse sentido, coloca-se como fundamento do interesse técnico na ordem do conhecimento que se pretende racional, visando à organização dos meios para alcançar possíveis metas ou objetivos previamente estabelecidos. A sistematização dos conhecimentos adquiridos no 
processo acumulativo de aprendizagem "[...] conduz a constituição das ciências empírico-analíticas, que caracteristicamente apontam a explicação causal e a predição condicional” (OLIVÉ, 1985, p. 145). Nesse contexto, Habermas não considera, como Herbert Marcuse, que o conhecimento técnico ou científico seja, na sua própria formulação, um conhecimento ideológico, mas equaciona o trabalho como "ação racional orientada por fins" (Zweckrationalität) e, desse modo, restringe o alcance do conhecimento técnico científico à esfera da racionalidade instrumental (GIDDENS, 1995, p. 249).

A teoria crítica da sociedade não deve e não pode limitar-se à manutenção de uma filosofia da história que tenha uma visão teleológica no sentido forte, ou seja, a pressuposição de um telos imanente ao desenvolvimento histórico, como o projetado por Marx. A teoria crítica levada adiante por Habermas busca ser fiel ao mesmo referencial advindo de seus pais fundadores - Adorno e Horkheimer - quanto ao potencial crítico e à possibilidade de emancipação inscrita na dimensão própria da teoria. A teoria crítica reivindica a possibilidade de diagnosticar a constelação histórica no momento presente e 'mostrar como as coisas são' a partir da perspectiva de 'como deveriam ser'. Portanto, ela agrega o potencial crítico, posto que se propõe a apresentar 'as coisas como são' dentro do delineamento histórico presente, e assegurar a perspectiva emancipatória ao sinalizar 'como as coisas deveriam ser'. Acresce ainda que essa perspectiva teórica somente encontra sua confirmação se vinculada à prática das relações sociais. (NOBRE, 2004, p. 27) É correto afirmar que não se pode creditar nem à teoria crítica nem a Habermas a fixação de um telos, nos moldes marxistas, que sinalizava onde deveria ocorrer o equacionamento final da sociedade. Porém, mesmo diante de tais limitações, não se pode abandonar uma teoria que aponte o possível desenvolvimento progressivo da sociedade, a não ser que se abra mão da perspectiva da emancipação, situando a teoria no nível meramente descritivo, como queria o positivismo.

A proposta de Habermas é deslocar a emancipação, que o marxismo havia atribuído às forças produtivas, para o âmbito das relações de produção, ou seja, ao campo dos argumentos sócio-morais. Porém, esse deslocamento amplia-se na ótica habermasiana, uma vez que são introduzidos os conceitos de trabalho e interação, os quais correspondem, respectivamente, às categorias marxistas de forças produtivas e relações de produção. Mesmo que o conceito de trabalho carregue em sua estrutura, de forma inerente, o modelo de racionalidade instrumental e seja o responsável pela reprodução material da sociedade, isso não significa, para Habermas, que ele esteja destituído completamente de condições emancipatórias. Contudo, a dimensão do trabalho não é emancipatória por 
si própria, mas dependente da dimensão interativa (HABERMAS, 1968). Isso é bastante significativo porque, como Habermas busca suporte para sustentar que o desenvolvimento social é resultado do progresso moral - estruturas normativas -, ele está, ao mesmo tempo, fortalecendo a dimensão prática da emancipação social inscrita na teoria crítica. É uma demonstração de que a teoria social não terá nenhum comprometimento com prognósticos futuros amarrados em pressupostos metafísicos ou teleológicos, mas tão somente com o pressuposto prático, no sentido de fornecer a sinalização dos bloqueios que impedem a efetiva realização da ação em direção à emancipação.

É manifesto que Habermas reconhece o papel de crítica do qual o pensamento de Marx é portador, no entanto, não admite que seja possível para uma teoria que pretende ser crítica, eleger como base paradigmática de análise o status científico proveniente das ciências naturais, restringindo, dessa forma, o alcance de sua reflexão tão somente à síntese do homem com a natureza pela categoria 'trabalho'.

Não tivesse Marx embaralhado interação e trabalho sob o denominador comum da práxis social, houvesse ele aplicado, em vez disso, o conceito materialista da síntese às realizações instrumentais e às inter-relações do agir comunicativo da mesma forma, então a idéia de uma ciência do homem não teria ficado obscurecida pela identificação com uma ciência da natureza (HABERMAS, 1982, p. 77).

Para Habermas, a filosofia deve preservar-se enquanto crítica e toda teoria da sociedade que reivindica ser uma auto-reflexão da história da espécie não pode simplesmente negar a filosofia. Sem desconsiderar a síntese técnica - produto da mediação entre homem e natureza -, Habermas almeja levar também em consideração, no plano da interação, a síntese prática - resultado da mediação entre os sujeitos no plano institucional e cultural.

Tendo Marx, portanto, reduzido a sua reflexão à dimensão do trabalho, restringiu inevitavelmente o escopo do seu pensamento teórico ao nível do agir instrumental. "[...] Marx interpreta, porém, aquilo que ele mesmo faz usando o modelo bem mais limitado de uma autoconstituição da espécie a realizar-se única e exclusivamente pelo trabalho. [...] Marx reduz o curso da reflexão ao nível do agir instrumental” (HABERMAS, 1982, p. 59-60). Não se espera daí - sinaliza Habermas - que seja possível brotar do paradigma da produção e do trabalho um processo de emancipação prático para o homem. "A emancipação relativamente à fome e à miséria não converge necessariamente para a libertação a respeito da servidão e da humilhação, pois não existe uma conexão evolutiva automática entre trabalho e interação" (HABERMAS, 1968, p. 46). Essa idéia de 
Habermas permanece sedimentada ao longo de seus escritos, podendo ser lida, por exemplo, em o Discurso Filosófico da Modernidade:

[...] a perspectiva da emancipação não se origina precisamente do paradigma da produção, mas do paradigma da ação orientada para o entendimento recíproco. E a forma dos processos de interação que tem de ser alterada, se se quer descobrir praticamente o que os membros de uma sociedade poderiam querer em cada situação e o que deveriam fazer no interesse comum. Torna-se mais clara a seguinte posição: 'Quando os homens, conscientes das pressões e limitações da sua situação de vida, determinam socialmente os objetivos e valores coletivos das suas ações por meio de uma articulação assim como de uma confrontação dialógica das suas necessidades, (só) então sua vida torna-se racional'. No entanto, uma teoria comprometida com o paradigma da produção nada poderá dizer a respeito da fundamentação dessa idéia de razão como uma idéia contida fatualmente nas relações de comunicação e que se apreende de modo prático (HABERMAS, 1968, p. 46).

A insistência de Habermas em manter as esferas de trabalho e interação separadas, apontando a heterogeneidade e a irredutibilidade de uma a outra é precisamente para evadir-se da possível junção de progresso técnico e comportamento racional da vida. Mantendo a postura, segundo a qual o progresso técnico por si não é portador de emancipação, Habermas sinaliza para as conseqüências que podem ser originadas da confluência entre trabalho e interação, destacando, como principal, a consolidação da ideologia tecnocrática.

Ainda em relação à Marx, autor que configura em grande parte o horizonte no qual se move a reflexão habermasiana, fica a decepção de não poder comprovar na atualidade a consolidação de uma sociedade alternativa ao capitalismo. $\mathrm{O}$ prognóstico da autodestruição do capitalismo por meio de suas inerentes crises econômicas e da organização das lutas de classes já não se configura como teoria decisiva para levar o marxismo adiante, necessitando antes de revisão e atualização do quadro categorial para explicar não mais um Estado liberal, e sim um Estado com fortes tendências intervencionistas.

Habermas percebeu que o caminho adotado por Marx quanto à emancipação do gênero humano estava bloqueada em sua possibilidade de realização. $\mathrm{O}$ caminho escolhido por Marx tende ao fracasso porque este elegeu apenas o nível de desenvolvimento das condições de trabalho - forças produtivas - como único critério possível de evolução e emancipação da sociedade. Nas condições em que o marxismo apresentou o itinerário da emancipação, Habermas reclama a necessidade de apresentar um outro nível categorial que dê conta de recuperar, no horizonte das sociedades capitalistas, as condições efetivas de sua emancipação. Para ele 
[...] não são, entretanto, novas tecnologias que demarcam o caminho do progresso da formação social, mas etapas progressivas da reflexão; por seu intermédio se suprime o caráter dogmático de formas de dominação e de ideologias superadas, a pressão do quadro institucional é sublimada e o agir próprio à comunicação libera-se como (um) agir que promove a comunicação propriamente dita. Com isto antecipa-se o objetivo de tal dinâmica, a saber: a organização da sociedade exclusivamente sobre a base de uma discussão livre de qualquer forma de dominação repressiva (HABERMAS, 1982, p. 70).

Contudo, Habermas deixa expressar que o capitalismo foi, na história mundial, o primeiro modo de produção que institucionalizou o crescimento econômico auto-regulado.

[...] Só depois de o modo de produção capitalista ter dotado o sistema econômico de um mecanismo regular, que assegura um crescimento da produtividade não isento sem dúvida de crises, mas contínuo a longo prazo, é que se institucionaliza a introdução de novas tecnologias e de novas estratégias, isto é, institucionalizase a inovação enquanto tal (HABERMAS, 1968, p. 67-68).

A corrosão do quadro institucional foi ocasionada pela sua incapacidade de gerenciar, dentro de seus limites legitimatórios, a expansão dos subsistemas de ação racional teleológica, acelerados sobremaneira pela dinâmica evolutiva das forças produtivas. As expansões desses subsistemas aliadas à estruturação de novas formas de produção solaparam as formas tradicionais de organização, fazendo com que tais subsistemas assumissem a direção e o controle social sob a marcha da racionalidade estratégica e instrumental. Os indivíduos foram pressionados a deslocar-se do contexto da interação mediado pelo quadro institucional para assumir o enfoque da ação racional dirigida a fins. A confrontação de interação com racionalidade ligada às relações meio/fim é assinalada por Habermas como ruptura da legitimação da dominação tradicional.

Desse modo, é possível constatar que a superioridade da produção capitalista está fundada em sua capacidade de ampliação e manutenção dos subsistemas - movidos pela lógica da racionalidade estratégica e instrumental -, o que faz romper os limites impostos pelo quadro institucional - amparado pela racionalidade comunicativa. A legitimidade alcança-se, agora, com a economia, pois a sociedade, tendo-a como base da organização de um mercado de trocas que chega a comportar a troca da força de trabalho daqueles para quem esta constitui a única mercadoria disponível, fez com que a economia se apresentasse como portadora de legitimidade, supondo dar garantias, a partir das relações de troca, a uma justiça de equivalência. Não obstante, essa aposta retirou a base política da sociedade, colocando em seu lugar uma base imediatamente econômica, o que deixa plenamente manifesta a dinâmica do Estado Liberal.

A diferente distribuição de riquezas entre as classes sociais, acentuada 
entre burguesia e proletariado, seria plenamente justificada, tomando-se o mercado como base de legitimação. Na concepção de Habermas, o problema da legitimação do capitalismo foi resolvido por uma singular fusão entre marco institucional (interação) e sistema econômico (trabalho).

Com a alteração do Estado liberal para o Estado intervencionista, o capitalismo modificou de maneira significativa a sua plataforma ideológica na legitimação do sistema. Abandonando a sua posição de mero expectador neutro diante de um mercado de trocas livres, o Estado, ele próprio, assumiu a direção do sistema econômico, buscando uma nova forma de equilíbrio para o sistema capitalista. Esse intervencionismo implica - na visão de Habermas numa repolitização do marco institucional, o que significa, em outros termos, que a troca de equivalentes já não podia manter a relevante tarefa que lhe foi concedida no Estado liberal: a de exercer a função de integração social.

Nessa nova fase, o Estado, que antes tendia a manter-se à margem do mercado e da distribuição desigual, passou a dispor de seu poder para intervir no movimento econômico e na mediação entre as partes antagônicas das classes sociais. A mudança que ocorreu nessa nova etapa do capitalismo foi a de que a sociedade já não era mais capaz de integrar-se pelo livre intercâmbio econômico, delegando tal tarefa à direção e à organização do poder estatal.

Se o mundo se tornou estranho, incompreensível, isto advém do corte representado pela instauração do capitalismo e por suas transformações históricas subseqüentes. Não se baseando numa forma de legitimação tradicional, o capitalismo exige que sua legitimação seja produzida juntamente com a produção material. Com o declínio do mercado, essa legitimação tem de ser produzida em outras instâncias que não a da produção econômica. Isto, entretanto, configura uma situação em que do indivíduo se requer sistemicamente o assentimento e, ao mesmo tempo, se declara ser ele supérfluo, substituível. Não sendo mais efetivamente possível uma apreensão da totalidade do modo de produção, produz-se apenas a consciência da impotência e do estranhamento, vale dizer, uma reificação da consciência produzida, por assim dizer, administrativamente, 'de cima' (NOBRE, 1998, p. 43-44).

Aspecto relevante a considerar nesse contexto é que no capitalismo liberal o Estado não necessitava de nenhuma justificativa direta, já que não exercia nenhum poder específico, a não ser o de mero observador e garantidor dos interesses privados sob a roupagem da troca justa de equivalentes. Entretanto, a partir da nova constelação que se apresenta, o Estado tem de buscar a legitimação do poder que exerce, de maneira direta, sobre o mercado e a sociedade. Não sendo possível recorrer às tradições, o Estado passa a se amparar, para a sua própria legitimação, em uma nova mentalidade aceita: a do progresso técnico.

Essa nova forma de legitimação reveste-se, na visão de Habermas, como 
ideologia, vale dizer, como ideologia tecnocrática, a qual somente se tornou possível com o desenvolvimento e entrelaçamento cada vez maior entre ciência, técnica e a sua utilização. Nesse sentido, ciência e técnica convertem-se na primeira força de produção e, também, possibilitam novamente a fusão entre as forças produtivas e o marco institucional. Nessa situação ilustrada alcançase um Estado tecnocrático que pretende legitimar a si mesmo por uma lógica imanente da dinâmica evolutiva técnico-científica.

É de se notar que a racionalidade dominadora, veiculada pelo pensamento técnico científico, gerou por si própria o fundamento de legitimação, qual seja: a associação do aceleramento das forças produtivas ao progresso tecnológico. Esses elementos legitimatórios conduziram, na verdade, a uma repressão dos indivíduos que, paradoxalmente, vêm-se desfazer da sua consciência, uma vez que vislumbram diante do trabalho e da tecnologia a possibilidade de uma vida mais 'confortável' materialmente.

A intervenção estatal na economia produz - segundo Habermas - a repolitização do quadro institucional, e este fato gera uma transformação bastante significativa na relação entre o sistema econômico e o sistema de dominação. Não se julga, a partir dessa transformação, que a política seja um fenômeno superestrutural, como queria Marx. A sociedade, deixando de ser vista como entidade autônoma, como estrutura que se mantém independente do Estado, leva de roldão a teoria de Marx que definia uma relação de base e superestrutura para o Estado e a sociedade. Habermas entende que o desenvolvimento de uma teoria crítica da sociedade baseada exclusivamente em uma crítica da economia política não mais satisfaz.

[...] Um tipo de análise, que isola metodicamente as leis do movimento econômico da sociedade, só pode pretender captar nas suas categorias essenciais o contexto da vida social quando a política depende da base econômica e não, inversamente, quando essa base se deve considerar já como função da atividade do Estado e de conflitos decididos na esfera do político (HABERMAS, 1968, p. 75-76).

A expressão de Habermas deixa entender que a teoria de Marx, acerca da infra e superestrutura, não é mais suficiente para dar conta da nova fase do capitalismo. Habermas demonstra desconfiança na prioridade que Marx havia concedido às forças produtivas e a categoria 'trabalho' como indicadoras do progresso material e, conseqüentemente, da própria emancipação. Não desconsiderando o papel que tal conceito exerce na dimensão de reprodução material da vida humana, Habermas indica já em Técnica e Ciência como Ideologia e mais detalhadamente em Para a Reconstrução do Materialismo Histórico que as forças produtivas devem ser substituídas por um conceito 
mais amplo e abstrato e igualmente ser complementadas por outro indicador igualmente decisivo (HELLER, 1997, p. 308).

A teoria marxista alcançou êxito quando se propunha a explicar o capitalismo no contexto do Estado liberal, fase na qual a infra-estrutura girava na órbita do econômico, mas se torna praticamente inviável quando trata de um capitalismo já avançado em sua forma intervencionista, em que a órbita dos fatos passou a gravitar em torno da política.

Com isso fica manifesto que do ponto de vista da teoria social crítica, nos moldes projetados por Habermas, não há possibilidade de se fazer uma leitura unilateral, contemplando apenas a dimensão do trabalho ou da interação na dinâmica social. Esses dois elementos são indispensáveis para a compreensão dos modelos de racionalidade que estão presente na dialética histórica do desenvolvimento do Estado. Como visto acima, a lógica do Estado Liberal esvaziou qualquer possibilidade de valorização da força de trabalho, na medida em que reduziu toda a força humana empregada na produção material a um componente mercantil passível de comercialização na arena do mercado. Com o Estado intervencionista é possível perceber significativas mudanças nesse sentido, sobretudo, quando se acompanha o trabalho e sua pretensão de valor agregado do ponto de vista constitucional. Estado e mercado passam a ser intermediados pela dimensão própria da esfera pública, das organizações sociais e dos movimentos trabalhistas que conseguiram lentamente assegurar, do ponto de vista jurídico, as conquistas de suas lutas.

\section{DOS MODELOS DE ESTADOS: LIBERAL E INTERVENCIONISTA}

Com o advento das Revoluções Francesa e Industrial, sedimentaram-se os conceitos do chamado Estado Liberal, embasados pelo pensamento do laissez faire, criando a chamada doutrina do "Estado mínimo", onde a autoridade estatal serviria unicamente para aumentar a taxa média de lucro, fomentar a acumulação de bens e capital e, ainda, estruturar-se para atender aos reclamos das classes sociais mais organizadas.

O Estado Liberal, com sua abstenção completa da esfera privada, precisava deixar o mercado e as relações desenvolvidas nesse âmbito econômico ao sabor

\footnotetext{
${ }^{1}$ Laissez faire, laissez passer, le monde va de lui même ("deixar fazer, deixar passar, o mundo caminha por si mesmo”) é uma expressão francesa, que denotava a exigência de um retraimento do Estado no âmbito social, surgida na segunda metade do século XVIII com o advento das revoluções burguesas, principalmente na Inglaterra, França e Estados Unidos da América do Norte, como base do pensamento liberal (VIEIRA, 2004, p. 196).
} 
da "mão invisível", isto é, o próprio mercado se auto-regularia e, por si só, encontraria meios de se desenvolver e possibilitar a vivência, em sua plenitude, dos valores da igualdade, liberdade e fraternidade. Pensavam os liberais que, apenas por meio da liberdade seria possível alcançar a implementação da igualdade, uma vez que o Estado, ao atuar interferindo na seara econômica, acabaria por conceder algum tipo de benefício ou gerar determinado privilégio que acabaria por desigualar os indivíduos.

Para evitar esse tipo de situação, o Estado de Direito surge com o movimento constitucionalista das Revoluções Burguesas como uma maneira de proteger os homens contra a ingerência do Estado, com a legislação dos Estados garantindo a todos os direitos fundamentais, baseados na liberdade, propriedade e igualdade - vista sob esse prisma de liberdade de atuação econômica que possibilita a equivalente possibilidade de consecução de recursos e bens -, bem como a obrigação de todos, inclusive do Estado, perante as leis.

$\mathrm{Na}$ esfera política a atuação também era bastante mitigada, com a intervenção acontecendo apenas quando se mostravam ameaçados os direitos à liberdade e propriedade dos indivíduos. O Estado deveria agir pontualmente, sanando eventuais problemas e, em seguida, abstendo-se de qualquer outro tipo de medida interventiva.

A abstenção estatal no setor econômico proporcionou sua emulação e desenvolvimento nas áreas técnica e científica, com o crescimento da produção e distribuição de bens. Contudo, a dinâmica do capitalismo deixado ao sabor do mercado teve como corolário crises nefastas, causando grandes mazelas sociais, como o crescimento da taxa de natalidade, a formação de grandes conglomerados urbanos, marcados por assombrosas desigualdades entre as classes operária e empresarial, resultando na equiparação da mão-de-obra a uma mercadoria qualquer, ou seja, na venda barata da força laboral para garantir a sobrevivência.

Nesse contexto, o pensamento marxista foi fundamental na crítica ao modelo liberal de Estado, sobretudo, em sua análise do trabalho como mercadoria ofertada pelo proletário aos proprietários dos bens de produção. Marx levou a cabo a crítica da ideologia burguesa na forma de economia política e alcançou êxito, ao desestruturar a ideologia da troca justa, de tal forma que o quadro legitimatório do capitalismo não pôde se sustentar duradouro na economia.

O capitalismo caracteriza-se, segundo Marx, pelo fato de retirar do céu as ideologias próprias às legitimações de domínio e violência palpáveis, trazendoas para dentro do sistema do trabalho social. Na sociedade liberal-burguesa a legitimação do poder é deduzida da legitimação do mercado, quer dizer, da 
'justiça' inerente às relações de troca da permuta equivalente. Esta justiça é desmascarada pela crítica ao fetiche da mercadoria (HABERMAS, 1982, p. 75).

É sob a rubrica dessa lógica estruturada ideologicamente que o trabalho, mais especificamente a força de trabalho, fora convertida em mercadoria.

A par da desestruturação da legitimidade do Estado liberal e da gênese da consciência política, tornando possível que o operariado se solidarizasse e organizasse sindicatos e cooperativas para exigir do Estado soluções aos conflitos instaurados entre capital e trabalho, ocorre uma mudança significativa na forma de o Estado atuar. (VIEIRA, 2004, p. 199) O Estado Social preconiza uma intervenção maior do Poder Público no âmbito econômico, haja vista a incapacidade de a economia, por si só, auto-regular-se e conseguir desenvolverse, ao mesmo tempo, de modo a garantir a justiça social.

Obviamente tais ideais foram gradativamente implementados, não acontecendo subitamente em razão de uma única transformação. Foi, sim, fruto de uma série de conquistas sociais, cujos pressupostos englobavam desde a preservação da livre concorrência das forças do mercado e a obrigação do Ente Público de ordenar e dirigir o processo econômico, até a observância e respeito aos valores de justiça social, bem estar e interesse públicos (GRAU, 1978, p. 18-20).

Somente após as Guerras Mundiais, a intervenção no domínio econômico foi acentuada e concretizada, com o mister de o Ente Público direcionar e organizar as atividades produtivas, estruturando-se não só em razão do embate global que se instalara, mas, outrossim, das crises e depressões dele advindas (VENÂNCIO FILHO, 1998, p. 10-1; SCAFF, 2001, p. 88).

Em prol do interesse coletivo e da justiça social, para garantir e propiciar a liberdade de iniciativa e o livre mercado, o Estado interveio mediante normas sociais e econômicas, inseridas nas constituições como forma de regulamentar as atividades, não se permitindo a extrapolação dos limites prescritos em lei (FONSECA, 2004, p. 260-261). Também chamada de democracia liberal, esse modelo visava à consolidação de uma política social embasada na igualdade entre os cidadãos, mitigando as desigualdades econômicas e sociais e protegendo os indivíduos com serviços e atividades de natureza pública em geral, sempre revestida por instrumentos legais a fim de restar prevalente o interesse público e as políticas sociais em detrimento das imposições do mercado capitalista (VIEIRA, 2004, p. 214-215). Essa nova tendência foi explicitada primeiramente na Constituição mexicana de 1917, posteriormente observada na Constituição de Weimar (1919). No Brasil, as idéias intervencionistas mostraram-se presentes somente na Constituição de 1934, disciplinadas no texto legal como Ordem 
Econômica e Social. Na seqüência, daremos atenção ao aspecto intervencionista do Estado, sob o ponto de vista constitucional, destacando, sobretudo, a realidade constitucional brasileira.

\section{INTERVENÇÃO DO ESTADO NO DOMÍNIO ECONÔMICO DO PONTO DE VISTA CONSTITUCIONAL: O CASO DO BRASIL}

A primeira Constituição brasileira que dispôs sobre o intervencionismo estatal, inserido numa ordem liberal, foi a de $1934^{2}$. Desde então, essa tendência intervencionista aparece nos posteriores textos constitucionais, até a atual Constituição da República Federativa do Brasil promulgada em 1988, cuja ordem econômica e financeira encontra-se balizada nos princípios constantes do Art. 170 do sobrecitado Texto Constitucional ${ }^{3}$.

A esse conjunto de preceitos constitucionais e instituições jurídicas que versam sobre os fenômenos de determinado sistema econômico atribui-se, na doutrina, a expressão Constituição Econômica. Nesta, encontram-se normas que determinam a forma de organização e funcionamento de dada ordem econômica (ELALI, 2007, p. 35).

É importante destacar que a ordem econômica de que trata o Art. 170 da Constituição Federal de 1988 não indica uma parcela da ordem jurídica como sua nomenclatura leva a crer. A expressão, em verdade, cinge a idéia de relações

${ }^{2}$ Constituição de 1934. Art. 116. Por motivo de interesse público e autorizado em lei especial, a União poderá monopolizar determinada indústria ou atividade econômica, asseguradas as indenizações devidas, conforme $\mathrm{o}$ art. 112, $\mathrm{n}$ 을 17 , e ressalvados os serviços municipalizados ou de competência dos Poderes locais. Art. 117. A lei promoverá o fomento da economia popular, o desenvolvimento do crédito e a nacionalização progressiva dos bancos de depósito. Igualmente providenciará sobre a nacionalização das empresas de seguros em todas as suas modalidades, devendo constituir-se em sociedades brasileiras as estrangeiras que atualmente operam no País. Parágrafo único. É proibida a usura, que será punida na forma da Lei.

${ }^{3}$ Constituição de 1988. Art. 170. A ordem econômica, fundada na valorização do trabalho humano e na livre iniciativa, tem por fim assegurar a todos existência digna, conforme os ditames da justiça social, observados os seguintes princípios: I soberania nacional; II - propriedade privada; III - função social da propriedade; IV livre concorrência; V - defesa do consumidor; VI - defesa do meio ambiente, inclusive mediante tratamento diferenciado conforme o impacto ambiental dos produtos e serviços de seus processos de elaboração e prestação; VII - redução das desigualdades regionais e sociais; VIII - busca do pleno emprego; IX - tratamento favorecido para as empresas de pequeno porte constituídas sob as leis brasileiras e que tenham sua sede e administração no País. Parágrafo único. É assegurado a todos o livre exercício de qualquer atividade econômica, independentemente de autorização de órgãos públicos, salvo nos casos previstos em lei. 
econômicas ou atividade econômica, demonstrando a realidade sistematizada pelos economistas, com normas - não jurídicas - que conduzem a economia. Ou seja, elas servem de indicação, retratando o mundo do ser, o modelo empírico de Economia, um modo de produção econômica (GRAU, 2004, p. 58-60).

Visualiza-se desse modo o intervencionismo presente no Estado Brasileiro, inferido do fato de as Constituições liberais sequer necessitarem explicitar em seus textos normas que compusessem a definição do que seria uma ordem econômica. A existente na realidade era suficiente, conquanto a atividade econômica permaneceria ao sabor das instituições privadas do mercado.

Isto ocorre porque, embora regido pelo modo de produção capitalista, o Estado deve intervir para realizar as atribuições sociais, econômicas, políticas e culturais almejadas pela sociedade. Consagram-se, nesse aspecto, os princípios básicos da ordem capitalista, quais sejam: a livre iniciativa e a propriedade privada, atuando como força motriz da ordem econômica brasileira, garantindo a livre atuação dos cidadãos no domínio econômico de maneira eqüitativa, contudo, ao mesmo tempo, o dispositivo constitucional preceitua a observância de princípios como a valorização do trabalho humano, a função social da propriedade, a defesa do consumidor, a defesa do meio ambiente e a busca do pleno emprego.

O intervencionismo presente no atual modelo de Estado e disposto no Texto Constitucional indica que, embora regido pelo sistema capitalista, o Poder Público pode e deve intervir no âmbito econômico, conforme os limites estabelecidos, para realizar as atribuições sociais de que se investiu em razão dos anseios e necessidades da sociedade e consoante aos próprios valores positivados na Constituição.

A preservação de tais valores reclama necessariamente a intervenção do Estado para coibir os abusos, preservar a livre concorrência, evitar a formação de monopólios e o abuso do poder econômico. O Estado pode intervir, entretanto, não de modo a acabar com a livre iniciativa, conquanto existam determinados graus de intervenção. Um maior grau intervencionista indica um modelo mais próximo de um Estado Social. Menor o grau de intervenção, mais próximo se está de um modelo de Estado Liberal.

Seja qual for a posição adotada pelo Estado entre esses dois extremos, a livre iniciativa não será suprimida, porque o Estado circunscrito a esses dois pólos não excede quanto à possibilidade de planificação da economia, típica dos Estados socialistas. Quando a posição do Estado é a de interventor, há necessidade de se entender as conseqüências dessa intervenção e de afetação das liberdades que serão recortadas segundo os limites constitucionais. 
Os princípios constitucionais da ordem econômica devem ser interpretados tendo em vista outros valores relativos à liberdade das atividades econômicas, mas, principalmente, tendo por foco as necessidades humanas - como provimento de serviços na área de educação, saúde, informação, cultura, etc - sempre utilizadas a fim de prestigiar o desenvolvimento econômico em consonância com a promoção da justiça social, sobretudo, fazendo valer a redução das desigualdades sociais.

Observa-se, ainda, como embasamento constitucional de que se vale o Estado para implementar essa intervenção, o Art. 173, trazendo a atuação estatal na atividade econômica em sentido estrito, em que considera o comportamento do Estado como se agente econômico fosse; e, por fim, mostrando que o Estado pode intervir na economia por meio de normas, com o intuito de reger a política econômica, tem-se o Art. 174, endossando o dever estatal de regulamentação normativa e justificando a fiscalização, o incentivo e o planejamento ${ }^{4}$.

A Constituição de 1934 ao tratar do intervencionismo estatal, o fez sob a intitulação de "Ordem Econômica e Social", na qual o Estado deveria atuar e influir no mercado, fomentando a economia popular (FONSECA, 2004, p. 261). A Carta seguinte, a de $1937^{5}$, além de inovar com a explicitação da expressão “intervenção do Estado no domínio econômico", prescreveu não somente o controle do Poder Público incidente na Economia, mas, igualmente, a instituição de crimes contra a economia popular (FONSECA, 2004, p. 262).

A Constituição de $1946^{6}$ balizou a atuação do Estado no domínio econômico,

\footnotetext{
4 "As intervenções consubstanciadas no exercício de funções de fiscalização, de incentivo e de planejamento cabem a todos os entes federados, observados os limites de competência prescritos pela Constituição Federal” (GASPARINI, 2004, p. 657).

${ }^{5}$ A Constituição de 1937 explicita tais aspectos em dois artigos, conforme dispostos a seguir: Art. 135. Na iniciativa individual, no poder de criação, de organização e de invenção do indivíduo, exercidos nos limites do bem público, funda-se a riqueza e a prosperidade nacional. A intervenção do Estado no domínio econômico só se legitima para suprir as deficiências da iniciativa individual e coordenar os fatores de produção, de maneira a evitar ou resolver os seus conflitos e introduzir no jogo das competições individuais o pensamento dos interesses da Nação, representados pelo Estado. A intervenção no domínio econômico poderá ser mediata e imediata, revestindo a forma do controle, do estímulo ou da gestão direta. Art. 141. A lei fomentará a economia popular, assegurando-lhe garantias especiais. Os crimes contra a economia popular são equiparados aos crimes contra o Estado, devendo a lei cominar-lhes penas graves e prescrever-lhes processos e julgamentos adequados à sua pronta e segura punição.

${ }^{6}$ Constituição de 1946. Art. 146. A União poderá, mediante lei especial, intervir no domínio econômico e monopolizar determinada indústria ou atividade. A intervenção terá por base o interesse público e por limite os direitos fundamentais assegurados nesta Constituição.
} 
podendo este fixar os limites da economia liberal e promover a livre iniciativa e a valorização do trabalho humano, porém, nunca investindo contra ou adentrando na esfera dos direitos fundamentais (FONSECA, 2004, p. 263).

Em 1967 a Constituição ${ }^{7}$ trouxe a lume, ladeado pelos princípios de liberdade de iniciativa e valorização do trabalho humano, o desenvolvimento econômico, transformando o Estado, até então regulador, em um competidor junto à iniciativa privada (FONSECA, 2004, p. 264).

A Emenda Constitucional no .1 de $1969^{8}$ substituiu o termo "desenvolvimento econômico" por "desenvolvimento nacional" e ainda acrescentou no Texto a ótica de justiça social, somadas à indispensabilidade - já observada na Constituição de 1967 -, preferencialidade e suplementariedade da atuação do Estado no campo econômico, com a imposição para tal de um regime privado para impedir o Poder Público de se privilegiar de algum modo - como a concorrência desleal (FONSECA, 2004, p. 265).

Já a Constituição de 1988 trouxe a possibilidade de intervenção estatal de modo direto na economia mediante o Art. 173 e de modo indireto (por meio de regulação, normatização, planejamento e incentivo) conforme dispõe o Art. 174.

Além da intervenção do Estado aparecer de modo destacado em todas as constituições brasileiras depois de 1934, faz-se mister um breve histórico de como a valorização do trabalho humano foi desenvolvida pelos Textos Constitucionais ao longo dos anos no Brasil.

\subsection{A Valorização Constitucional do Trabalho Humano}

A Constituição de 1934 dispõe em seu título IV "Da Ordem Econômica e Social" que as questões econômicas deviam ser tratadas juntamente com as

7 Constituição de 1967. Art. 157. A ordem econômica tem por fim realizar a justiça social, com base nos seguintes princípios: I - liberdade de iniciativa;II - valorização do trabalho como condição da dignidade humana;III - função social da propriedade;IV - harmonia e solidariedade entre os fatores de produção;V - desenvolvimento econômico;VI - repressão ao abuso do poder econômico, caracterizado pelo domínio dos mercados, a eliminação da concorrência e o aumento arbitrário dos lucros.

${ }^{8}$ Emenda no 1 de 1969, Art. 170. Às empresas privadas compete, preferencialmente, com o estímulo e apoio do Estado, organizar e explorar as atividades econômicas. §1 $1^{o}$ Apenas em caráter suplementar da iniciativa privada o Estado organizará e explorará diretamente a atividade econômica. $§ 2^{\circ} \mathrm{Na}$ exploração, pelo Estado, da atividade econômica, as empresas públicas e as sociedades de economia mista reger-se-ão pelas normas aplicáveis às empresas privadas, inclusive quanto ao direito do trabalho e ao das obrigações. $3^{\circ} \mathrm{A}$ empresa pública que explorar atividade não monopolizada ficará sujeita ao mesmo regime tributário aplicável às empresas privadas. 
sociais e garantidas pelo Estado de maneira bastante generalizada. Pela leitura que se faz dos dispositivos 115 e 138 do Texto Constitucional de 1934, a vida digna e a liberdade econômica estavam asseguradas constitucionalmente, enquanto os demais os valores, circunstanciados de acordo com a necessidade da época, eram estabelecidos com destinação a receberem tratamento na legislação infraconstitucional. Não havia ainda nada especificamente a respeito da valorização do trabalho humano, contudo, a semente da proteção de muitos direitos sociais já estava posta. ${ }^{9}$

Com relação à Carta 1937, houve uma separação entre a ordem social e a ordem econômica em termos de disposição no Texto Constitucional, que passou a dispor em seu Art. 136, no item "Da Ordem Econômica", o trabalho como um dever social e, portanto, uma forma de garantia de subsistência que deve ser protegida pelo Estado. Isso demonstra que além de ser assegurado o direito de sobrevivência por intermédio do trabalho, o Estado deveria fornecer meios para que essas condições favoráveis estabelecidas no Texto Constitucional fossem atendidas. ${ }^{10}$

A Constituição de 1946 trouxe novamente em seu Título V "Da Ordem Econômica e Social” o trabalho como uma obrigação social necessária à manutenção de uma vida digna e determinou, no caput do Art. 145, que a ordem econômica deveria ser organizada consoante os valores de justiça social, livre iniciativa e a valorização do trabalho humano. Portanto, foi a primeira Constituição que trouxe este valor explicitamente no texto constitucional. ${ }^{11}$

9 Constituição de 1934. Art. 115 - A ordem econômica deve ser organizada conforme os princípios da Justiça e as necessidades da vida nacional, de modo que possibilite a todos existência digna. Dentro desses limites, é garantida a liberdade econômica. Art. 138Incumbe à União, aos Estados e aos Municípios, nos termos das leis respectivas: a) assegurar amparo aos desvalidos, criando serviços especializados e animando os serviços sociais, cuja orientação procurarão coordenar; b) estimular a educação eugênica; c) amparar a maternidade e a infância; d) socorrer as famílias de prole numerosa; e) proteger a juventude contra toda exploração, bem como contra o abandono fisico, moral e intelectual; f) adotar medidas legislativas e administrativas tendentes a restringir a moralidade e a morbidade infantis; e de higiene social, que impeçam a propagação das doenças transmissíveis; g) cuidar da higiene mental e incentivar a luta contra os venenos sociais.

${ }^{10}$ Constituição de 1937. Art 136 - O trabalho é um dever social. O trabalho intelectual, técnico e manual tem direito a proteção e solicitude especiais do Estado. A todos é garantido o direito de subsistir mediante o seu trabalho honesto e este, como meio de subsistência do indivíduo, constitui um bem que é dever do Estado proteger, assegurandolhe condições favoráveis e meios de defesa.

${ }^{11}$ Constituição de 1946. Art 145 - A ordem econômica deve ser organizada conforme os princípios da justiça social, conciliando a liberdade de iniciativa com a valorização do trabalho humano.

Parágrafo único - A todos é assegurado trabalho que possibilite existência digna. O trabalho é obrigação social. 
Não foi diferente com a Constituição de 1967, a qual trouxe a valorização do trabalho humano como base da ordem econômica, cuja finalidade assentavase na realização da justiça social. Pode-se inferir pela leitura do Art. 157 que a efetivação desse valor dependia da observância de todos os princípios dispostos em seus incisos, como, por exemplo, a liberdade de iniciativa, dignidade humana, função social da propriedade, dentre outros. ${ }^{12}$

A Emenda Constitucional oㅜ 1, de 1969, trouxe algumas mudanças, como a inserção do "desenvolvimento nacional" juntamente com a justiça social no caput do Art. 160 que dispunha sobre a finalidade da ordem econômica e social. Além da valorização do trabalho humano prevista no inciso II do sobredito artigo, a expansão das oportunidades de emprego produtivo - determinada no inciso VI e que, hodiernamente, já teria certa equivalência à preocupação que desemboca na atual "busca do pleno emprego" trazida pela Constituição de 1988 - veio reforçar o valor que a proteção e fomento ao trabalho adquiriu com o passar do tempo e a necessidade que se impôs ao Estado de garanti-la e implementá-l $a^{13}$.

Finalmente, a Constituição de 1988 pormenorizou as determinações acerca da ordem econômica, separando a "Ordem Econômica e Financeira" constitucional da ordem social e demonstrando no Capítulo I do Título VII que a atividade econômica no Brasil deverá ser conduzida segundo determinados princípios. Percebe-se pela leitura do texto constitucional a instituição de uma ordem jurídico-econômica apontando quais serão as diretrizes a serem seguidas pelo Estado e pelos agentes privados na busca de uma ordem econômica que supra esses valores almejados.

No Art. 170 do Texto Constitucional de 1988 a valorização do trabalho humano veio a fundamentar a ordem jurídico-econômica constitucional de

${ }^{12}$ Constituição de 1967. Art. 157 - A ordem econômica tem por fim realizar a justiça social, com base nos seguintes princípios: I - liberdade de iniciativa; II - valorização do trabalho como condição da dignidade humana; III - função social da propriedade; IV - harmonia e solidariedade entre os fatores de produção; V - desenvolvimento econômico; VI - repressão ao abuso do poder econômico, caracterizado pelo domínio dos mercados, a eliminação da concorrência e o aumento arbitrário dos lucros.

${ }^{13}$ Emenda $\mathrm{n}^{\circ} 1$ de 1969, Art. 160. A ordem econômica e social tem por fim realizar o desenvolvimento nacional e a justiça social, com base nos seguintes princípios: I - liberdade de iniciativa;II - valorização do trabalho como condição da dignidade humana;III - função social da propriedade;IV - harmonia e solidariedade entre as categorias sociais de produção; $\mathrm{V}$ - repressão ao abuso do poder econômico, caracterizado pelo domínio dos mercados, a eliminação da concorrência e ao aumento arbitrário dos lucros; e VI - expansão das oportunidades de emprego produtivo. 
forma a assegurar a todos os indivíduos uma existência digna e a legitimar o desenvolvimento das atividades econômicas no Estado. Assim, além de todos os princípios prescritos nos incisos do Texto Constitucional, a valorização do trabalho humano passou a servir de guia às atividades privadas nas relações com o mercado e também com o Estado, mediante a criação de empregos e implementação de políticas públicas que primam pelo desenvolvimento desse valor.

\subsection{Arcabouço Normativo de Proteção à Valorização do Trabalho Humano}

Além do Art. 170 da Constituição Federal analisado dentro de uma perspectiva histórica de desenvolvimento do princípio da valorização do trabalho humano e como fundamento de uma ordem jurídica econômica constitucional, podese verificar outros dispositivos no Texto Constitucional que primam pela sua valorização mesmo que de maneira indireta.

A começar pelo Preâmbulo da Constituição Federal ${ }^{14}$, o qual prescreve que o Estado está a serviço dos cidadãos e, portanto, dispõe de algumas atribuiç̧ões, como a de assegurar o exercício dos direitos sociais - dentre eles o direito ao trabalho digno -, o desenvolvimento - que tem em seu bojo a idéia de crescimento econômico, mas também a de justiça social e demais princípios que primam pelo desenvolvimento social - e outros valores relevantes alçados ao patamar de superioridade e fins precípuos de uma sociedade.

Prova disto é o disposto no Art. ${ }^{1015}$, o qual traz a valorização do trabalho humano como um dos fundamentos da República Federativa do Brasil e, interpretando de maneira ampla, pode ser entendido como embasamento dos objetivos da República, uma vez que o "desenvolvimento nacional" almejado no Art. $3^{\text {ol16}}$, II da Constituição Federal determina que o Estado objetiva

14 "Nós, representantes do povo brasileiro, reunidos em Assembléia Nacional Constituinte para instituir um Estado Democrático, destinado a assegurar o exercício dos direitos sociais e individuais, a liberdade, a segurança, o bem-estar, o desenvolvimento, a igualdade e a justiça como valores supremos de uma sociedade fraterna, pluralista e sem preconceitos, fundada na harmonia social e comprometida, na ordem interna e internacional, com a solução pacífica das controvérsias, promulgamos, sob a proteção de Deus, a seguinte CONSTITUIÇÃO DA REPÚBLICA FEDERATIVA DO BRASIL". (Grifo nosso)

${ }^{15}$ Art. $1^{\circ}$ A República Federativa do Brasil, formada pela união indissolúvel dos Estados e Municípios e do Distrito Federal, constitui-se em Estado Democrático de Direito e tem como fundamentos. I - a soberania; II - a cidadania; III - a dignidade da pessoa humana; IV - os valores sociais do trabalho e da livre iniciativa; $\mathrm{V}$ - o pluralismo político. (Grifo nosso)

${ }^{16}$ Art. $3^{\text {o }}$ Constituem objetivos fundamentais da República Federativa do Brasil: I construir uma sociedade livre, justa e solidária; II - garantir o desenvolvimento nacional; III - erradicar a pobreza e a marginalização e reduzir as desigualdades sociais e regionais; 
garantir o desenvolvimento nacional, o qual para ser alcançado deve ter como balizamento alguns princípios como a justiça social, a dignidade da pessoa humana e, certamente, a valorização do trabalho humano.

Já no Título II "Dos Direitos e Garantias Fundamentais", Capítulo II "Dos Direitos Sociais", o Art. $6^{\text {o17 }}$ prescreve o trabalho como direito social. Isto quer significar que é atribuição do Estado garantir aos indivíduos o direito ao trabalho, seja fomentando-o mediante positivação de normas que estabeleçam regras mínimas à valorização do trabalho humano (Art. 174), seja por meio de políticas públicas dos Governos para implementar o pleno emprego e outras medidas criadoras e protetoras do trabalho.

Há ainda importante questão que permeia o estudo dos princípios da "Ordem Econômica e Financeira" da Constituição Federal a ser suscitada, principalmente no concernente a um possível embate entre os valores "livre iniciativa" e "valorização do trabalho humano". A discussão se estabelece quando do momento de criação de políticas públicas que venham a prestigiar um em detrimento do outro e vice-versa, pois entendimentos existem no sentido de que seriam ambos incompatíveis, na medida em que um protegeria a liberdade de mercado, enquanto o outro lhe traria entraves.

Em verdade, não ocorre esse choque principiológico, haja vista que a valorização do trabalho humano deve ser priorizada em detrimento de qualquer outro princípio vigente na economia de mercado. Mesmo porque sem se obedecer a essa premissa, a sociedade correria o risco de regredir e perder muitos dos direitos conquistados à custa de lutas passadas.

Esta assertiva fica mais bem esclarecida, quando tomada em consideração à finalidade da ordem econômica, que deve estar direcionada à potencialização do homem, seja em sua dignidade existencial, seja na substantivação das qualidades que o singularizam - humanidade - mais bem percebida no quadrante solidarista e fraternal da justiça social (PETTER apud MORAES, 2008, p. 47).

Deve-se levar em conta, outrossim, que ao mesmo tempo em que a Constituição Federal consagra o princípio básico da ordem capitalista - que é a iniciativa privada - dá prioridade ao valor do trabalho humano sobre os demais valores. A preservação de tais valores conduziria a um regime estatal de defesa da livre iniciativa, mas que admitisse a intervenção do Estado para coibir

IV - promover o bem de todos, sem preconceitos de origem, raça, sexo, cor, idade e quaisquer outras formas de discriminação. (Grifo nosso).

${ }^{17}$ Art. $6^{o}$ São direitos sociais a educação, a saúde, o trabalho, a moradia, o lazer, a segurança, a previdência social, a proteção à maternidade e à infância, a assistência aos desamparados, na forma desta Constituição. (Grifo nosso). 
os abusos, preservar a livre concorrência, evitar a formação de monopólios e o abuso do poder econômico, repudiando o dirigismo estatal, mas admitindo a liberdade de mercado somente quando exercida no interesse da justiça social. "Isso significa que a livre iniciativa não é tomada, enquanto fundamento da República Federativa do Brasil, como expressão individualista, mas sim naquilo que expressa de socialmente valioso (GRAU, 2004, p. 200).

Finalmente, tem-se o Art. 193 da Constituição Federal prescrevendo que " $A$ ordem social tem como base o primado do trabalho, e como objetivo o bemestar e a justiça sociais”. (Grifo nosso)

Analisando os artigos da Constituição, percebe-se que embora haja uma preocupação com a livre iniciativa, livre concorrência, propriedade privada e outros dispositivos que mostrem a necessidade da manutenção de um sistema de mercado, o modelo de Estado brasileiro ainda possui muitas atribuições fruto do Estado Social, porquanto existe uma série de princípios que focam, sobretudo, a justiça social, a erradicação da pobreza, a distribuição de renda, a redução das desigualdades, os direitos sociais, etc.

Isso mostra que o Estado explicita por meio de seu ordenamento jurídico a existência de direitos fundamentais herdados do Estado Liberal, direitos sociais, políticos e culturais derivados das lutas sociais pós-guerras mundiais, enfim, que não se pode atribuir ao Estado brasileiro um modelo de Estado específico, mas dizer que ele possui como atribuições cumprir e implementar todos esses valores da sociedade e isso o torna um Estado que busca vivenciar um padrão, o Paradigma do Estado Democrático de Direito visando ao desenvolvimento nacional.

Para tanto, existe a necessidade de se positivar esses valores por meio de políticas públicas, mais especificamente aquelas relacionadas à implementação da valorização do trabalho humano e, ainda, observar que existe o mister de o Estado fomentar o vivenciamento desses princípios mediante a ajuda da atividade empresarial.

\subsection{Positivação da Valorização do Trabalho Humano por Meio de Propostas de Políticas Públicas}

A intervenção do Estado sobre o domínio econômico, no tocante às relações de trabalho, é uma necessidade, tendo em vista, principalmente que o olhar sob a perspectiva do trabalho humano deve ser publicista, segundo a análise da conjugação dos Arts. 1ํㅜ 3 , 170 e 193 da CF. Esta implementação na prática, no entanto, dar-se-ia mediante execução de políticas públicas de qualificação profissional e promulgação de normas protetivas do trabalho humano. Normas estas que não devem admitir retrocesso e/ou flexibilização da legislação 
trabalhista, haja vista a proteção aos direitos fundamentais trazida pela Constituição Federal. Somente por meio da valorização do trabalho humano poder-se-á atingir os objetivos determinados pelo Art. 3ㅜㅡ, CF, sustentáculo da República Federativa do Brasil.

Segundo o Art. 170, CF, a valorização do trabalho humano é um dos fundamentos da ordem econômica brasileira. Este preceito constitucional ligase diretamente ao Art. 3o, CF já que os objetivos fundamentais da República Federativa do Brasil ali relacionados - sociedade justa, livre e solidária, desenvolvimento nacional, erradicação da pobreza, marginalização, redução das desigualdades sociais regionais, bem estar e combate à discriminação são atingidos por meio da valorização do trabalho humano, fundamento da República Brasileira, segundo Art. 1ำ CF.

O trabalho valorizado é o trabalho que vem revestido de dignidade, visto que ocupa grande espaço na vida do indivíduo e, tendo seu ritmo ditado pelo paradigma de produção capitalista, deve refletir ainda em diversos setores da vida social.

A dignidade no trabalho é atingida, inicialmente, com a geração de mais postos de trabalho (Art. 6을 $\mathrm{CF}$ ), com a promoção da liberdade de escolha do trabalho e o modo de realizá-lo quando de seu exercício, garantindo maior satisfação e menor risco ao trabalhador, notadamente por meio de normas de higiene, saúde (em seu aspecto físico e no tocante à salubridade) e segurança (Art. 7으, XXII, CF).

É digno que o trabalho seja exercido criativamente (de modo que o trabalhador possa se expressar por meio dele e mostrar sua importância perante a sociedade), no qual exista a participação do trabalhador no gerenciamento empresarial (Art. 7º, XI, CF), onde o indivíduo encontre-se livre de qualquer espécie de discriminação (em relação a salários, critérios de admissão, pessoas portadoras de deficiência, discriminação entre trabalho braçal e trabalho intelectual (Art. 7o, XXXI e XXXII, CF), fomentado mediante a efetivação de políticas públicas de qualificação de mão-de-obra e passível de melhor retribuição do trabalho (proporcionalidade de retribuição entre os diversos empregos).

Um exemplo de intervenção do Estado nesse aspecto é quando ocorre o desemprego estrutural, caracterizado como uma desnecessidade da ocupação da função que dado trabalhador exerce em determinado modo de produção, ou seja, aquilo que o(s) trabalhador(es) sabe(m) fazer não é mais necessário que seja executado. O desemprego estrutural é causado, principalmente, pela mudança do sistema produtivo, no qual se observa a adoção de inovações tecnológicas e organizacionais pelas empresas. 
Esta reorganização e modernização tecnológica, resultantes de abertura econômica, alteram a utilização da racionalidade, passando ao exercício de uma lógica de "produção enxuta", baseada no toyotismo (menor número de empregados, maior especialização do trabalho, maior qualificação da mão de obra, etc). Atualmente, o "mundo do trabalho" passa por esta reestruturação produtiva, o que, por sua vez, gera uma exclusão social (ALVES, 2000, p. 259264).

Neste contexto quando se fala em intervenção do Estado no domínio econômico, não se fala apenas do prescrito no Art. 173, CF, mas também do direito do trabalho humano que influencia diretamente a economia. As alternativas para valorização do trabalho humano, a despeito da tendência quanto à redução dos postos de emprego, são:

a) os constantes programas de requalificação do trabalhador, mesmo durante a ocupação de seu posto de trabalho;

b) a construção de um ambiente de trabalho digno e criativo;

c) a criação de mecanismos que proporcionem ao trabalhador participar da formação das decisões da empresa em que trabalha.

Outra forma de intervenção seria a concessão de incentivos fiscais ou quaisquer outros tipos de benefícios, por meio de determinada política econômica, condicionando a autonomia privada a um agir com respeito aos valores substanciais ligados à pessoa humana, não no sentido básico (cumprimento apenas de sua função social), mas promovendo cursos de especialização ou qualificação profissional aos seus empregados, por exemplo.

Subemprego também é um dos problemas que se mostra bastante presente na sociedade e que precisa de soluções do Estado. Consiste na condição econômica situada entre o emprego e o desemprego. Ocorre normalmente quando o empregado não tem recursos ou meios para se manter desocupado enquanto procura emprego, vindo a exercer qualquer tipo de atividade da economia informal em função da necessidade de sobrevivência.

A temporariedade da situação torna-se definitiva quando o trabalhador não consegue mais voltar à economia formal, transformando o subemprego em modo de vida. Geralmente o subemprego atinge trabalhadores com renda inferior e, portanto, acarreta grande dificuldade em obter qualificação e/ou maior grau de escolaridade e, conseqüentemente, são reduzidas as chances de ascensão profissional.

Esses empregos geram um mercado paralelo onde circulam divisas consideráveis, garantindo a renda de muitas famílias. A diversidade e a descontinuidade das formas de emprego estão em vias de suplantar o paradigma 
do emprego homogêneo e estável. São estruturais e devastadores os efeitos sobre o mercado de trabalho do atual padrão flexível de produção associado aos processos de desregulamentação das relações econômicas.

Esses efeitos são ainda mais intensivos e extensivos em países latinoamericanos com sistemas de proteção social incompletos, submetidos a rígidos controles fiscais e com economias mais vulneráveis à abertura de seus mercados. Embora fosse preferível que o Estado gerasse novos empregos formais, a dificuldade de que isso venha a ocorrer e a gravidade da situação impõem, muitas vezes, a criação de quaisquer ocupações - excetuando-se as criminosas -, capazes de gerarem renda.

E mesmo a geração de novas ocupações serviria para diminuir a pressão da oferta de mão-de-obra sobre o mercado de trabalho. $\mathrm{O}$ combate ao desemprego por essa via corre o risco de não conseguir se diferenciar do discurso empresarial de que o caminho para geração de emprego passa pela flexibilização das relações trabalhistas. A combinação entre desemprego e subemprego tornou-se funcional à dinâmica do mercado desregulamentado, onde as empresas buscam sem cessar reduzir custos.

Para além da promoção de políticas sociais que proporcionem acesso a bens e serviços essenciais, deve-se fazer valer, no caso de assalariados, direitos já instituídos e reivindicar outros ainda por instituir aos não-assalariados. Isso não significa cuidar somente daqueles que já se encontram ocupados, deixando os desempregados em segundo plano. Ao contrário, entende-se que esse é o caminho mais efetivo para enfrentar o desemprego. Além disso, o foco privilegiado no combate ao subemprego não dispensa, obviamente, a geração de novas ocupações. Eis o caminho que vetoriza a superação do subemprego por meio da valorização do trabalho humano preconizado no Art. 170 da Constituição Federal.

Para sugerir de que forma o combate ao subemprego mostra-se hoje estratégico na luta contra o desemprego, é preciso ter em conta as naturezas distintas da precarização no que toca ao trabalho assalariado em relação ao não-assalariado. Os efeitos sobre a geração de empregos em cada um dos casos são, embora interligados, de qualidade distinta. De um lado, direitos sociais e trabalhistas assegurados pelo contrato formal de trabalho tendem a ser flexibilizados e mesmo não atribuídos a trabalhadores assalariados. De outro, formas não-assalariadas de trabalho como trabalho autônomo, por conta própria, cooperativado, familiar, do micro-empreendedor, etc, são largamente desenvolvidas sem que estejam suficiente ou minimamente reguladas.

Então, no primeiro caso, trata-se de direitos instituídos que precisam ser 
respeitados e, no segundo, de direitos instituintes que precisam ser reconhecidos e promovidos. Assim, é necessário fortalecer os direitos instituídos, fiscalizar e, efetivamente, punir as empresas que estão na ilegalidade. Constituiria ingenuidade desconhecer que, pressionando tais ações, existe o profundo desequilíbrio entre capital e trabalho em favor do primeiro. O que se está propondo é exatamente que haja ações públicas que reduzam esse desequilíbrio com o argumento de que assim, e não ao contrário, é que haverá mais empregos e se superará o subemprego ${ }^{18}$.

Há também outros tipos de políticas públicas de inclusão e valorização do trabalho humano, como leis que tratam sobre determinadas cotas a serem cumpridas pelas empresas no emprego de deficientes físicos. Da mesma forma, há algum tempo atrás, esse mesmo tipo de política de inclusão foi feita em prol das mulheres, a fim de que pudessem trabalhar gozando das mesmas prerrogativas que os homens, não devendo existir redução de salário ou qualquer tipo de desconforto no ambiente de trabalho (DUARTE DA SILVA, 2006).

Portanto, verifica-se que existem ainda inúmeros problemas envolvendo o trabalho humano e que clamam por soluções. Não há como conjecturar a existência de um modelo de Estado essencialmente Liberal, no qual a economia seja auto-regulada e que o trabalho humano seja novamente colocado como mercadoria a ser negociada na esfera do mercado. Os direitos sociais, principalmente a valorização do trabalho humano, devem ser promovidos mediante a intervenção do Estado quando da promoção de políticas públicas que fomentam a criação de empregos - busca do pleno emprego - e visam a consolidar melhores condições aos postos de trabalhos já existentes. As racionalidades que permeiam ambos os modelos de Estado e também as duas dimensões da sociedade - sistêmica e mundo da vida - responsáveis, reciprocamente, pela reprodução material e simbólica da vida, devem ocupar uma relação dialética equilibrada que, segundo Habermas, é alcançável somente no pleno funcionamento da esfera pública, lócus de preservação, manutenção e solicitação de novas conquistas e direitos sociais.

Parte do material do item 3 deste trabalho foi baseado nas aulas do Prof ${ }^{a}$ Dr. Lourival José de Oliveira, ministradas nos dias 20/11/2007 e 26/11/2007, na disciplina Intervenção do Estado no Domínio Econômico, do Curso de Mestrado em Direito Negocial da Universidade Estadual de Londrina. 


\section{REFERÊNCIAS}

ALVES, Giovanni. O novo (e precário) mundo do trabalho: reestrututação produtiva e crise do sindicalismo. São Paulo: Boitempo editorial, 2000.

DUARTE DA SILVA, Gil. Responsabilidade social da empresa perante seus funcionários. Revista $T R T 9^{\circ}$ R., Curitiba, ano 31, n. 56, p. 207-40, jan./jun. 2006.

ELALI, André. Tributação e regulação econômica: um exame da tributação como instrumento de regulação econômica na busca da redução das desigualdades regionais. São Paulo: MP Editora, 2007.

FONSECA, João Bosco Leopoldino da. Direito Econômico. 5. ed. rev. e atual. Rio de Janeiro: Forense, 2004.

GASPARINI, Diógenes. Direito administrativo. 9. ed. rev. e atual São Paulo: Saraiva, 2004.

GRAU, Eros Roberto. A ordem econômica na Constituição de 1988 (interpretação e crítica). 9. ed. São Paulo: Malheiros, 2004.

GIDDENS, Anthony. Politics, sociology and social theory. Encounters with classical and contemporary social thought. California: Stanford University Press, 1995.

HABERMAS, Jürgen. Conhecimento e interesse. Introdução e Tradução de José N. Heck. Rio de Janeiro: Zahar Editores, 1982.

. O discurso filosófico da modernidade. Tradução de Luiz Sérgio Repa e Rodnei Nascimento. São Paulo: Martins Fontes, 2002.

. Technik und Wissenschaft als 'Ideologie'. Frankfurt am Main: Suhrkamp Verlag, 1968.

. Técnica e Ciência como 'Ideologia'. Tradução de Artur Morão. Lisboa: Edições 70, 1997.

. Arbeit und Interaktion. Bemerkungen zu Hegels Jenenser 'Philosophie des Geistes'. In: . Technik und Wissenschaft als 'Ideologie'. Frankfurt am Main: Suhrkamp Verlag, 1968. Tradução em língua portuguesa em: HABERMAS, Jürgen. Trabalho e Interação. In: Técnica e Ciência como 'Ideologia'. Tradução de Artur Morão. Lisboa: Edições 70, 1997.

HELLER, Agnes. Habermas y el marxismo. In: . Crítica de la Ilustración: 
las antinomias morales de la razón. Traducción de Gustau Muñoz y José Ignacio López Soria. Barcelona: Ediciones Península, 1997.

MORAES, Débora Brito. A valorização do trabalho como condição para a efetivação do princípio da dignidade da pessoa humana e o papel do Estado na valorização do trabalho. 2008. Dissertação (Mestrado em Direito) - UNIMAR.

MORAES, Débora Brito; OLIVEIRA, Lourival José de. Aspectos sobre a valorização do trabalho humano. Rivista Diritto \& Diritti. Disponível em: <http://www.diritto.it/archivio/1/24024.pdf>. Acesso em:

NOBRE, Marcos. A dialética negativa de Theodor W. Adorno. A ontologia do Estado Falso. São Paulo: Iluminuras, 1998.

. Teoria crítica. São Paulo: Jorge Zahar, 2004.

OLIVÉ, Leon. Estado, legitimación y crisis: crítica de tres teorías del Estado capitalista y de sus presupuestos epistemológicos. México: Siglo Veintiuno Editores, 1985.

OLIVEIRA, Lourival José de. Intervenção do Estado no domínio econômico e a valorização do trabalho humano. Londrina, 2007. Anotações efetuadas em aulas ministradas nos dias 20/11/2007 e 26/11/2007, na disciplina Intervenção do Estado no Domínio Econômico do Curso de Mestrado em Direito Negocial da Universidade Estadual de Londrina.

SCAFF, Fernando Facury. Responsabilidade civil do estado intervencionista. 2. ed. rev. e ampl. Rio de Janeiro: Renovar, 2001.

VENÂNCIO FILHO, Alberto. A intervenção do Estado no domínio econômico: Direito Público Econômico no Brasil. Ed. fac-similar. Rio de Janeiro: Renovar, 1998.

VIEIRA, Evaldo. Direitos e política social. São Paulo: Cortez, 2004.

Artigo recebido em 20/08/09 e aceito em 24/08/09 